Enfermagem Brasil 2018;17(4):413-20

\title{
ATUALIZAÇÃO \\ Evolução das políticas públicas à pessoa idosa no Brasil
}

Ewerton Naves Dias*, José Luís Pais-Ribeiro, D.Sc. ${ }^{*}$

*Doutorando em Psicologia pela Faculdade de Psicologia e Ciências da Educação da Universidade do Porto, Portugal, Docente da Universidade de Mogi das Cruzes, São Paulo, **Docente da Faculdade de Psicologia e de Ciências da Educação da Universidade do Porto, Porto, Portugal

Recebido em 5 de maio de 2017; aceito em 27 de dezembro de 2017.

Endereço para correspondência: Ewerton Naves Dias, Rua Alfredo Allen, Faculdade de Psicologia, 4200-135 Porto, Portugal, E-mail: ewertonnaves@gmail.com

\section{Resumo}

A maior longevidade populacional é uma das maiores conquistas da humanidade, devido aos avanços tecnológicos e científicos as pessoas passaram a viver mais tempo. No Brasil essa realidade não é diferente, o país caminha a passos largos para se tornar um dos países com maior percentual de idosos em sua população. $O$ aumento dessa faixa etária traz consigo novos desafios para toda sociedade, por isso tornou-se essencial discutir na atualidade sobre as políticas públicas as pessoas idosas. Diante desse contexto, este estudo teve como objetivo descrever por meio de uma revisão de literatura, sobre a evolução das políticas públicas ao idoso no Brasil. Concluiu-se que as políticas públicas para os idosos no Brasil avançaram significativamente nas últimas décadas. A constituição Federal de 1988, A Política Nacional do Idoso, o Estatuto do Idoso e a Política Nacional de Saúde da Pessoa Idosa foram as principais conquistas desse processo. Entretanto, apesar dos avanços e conquistas, na prática a garantia dos direitos dos idosos ainda não tem se concretizado de forma efetiva. Por esse motivo, a operacionalização das políticas públicas continua a ser o principal desafio a ser superado, pois, somente assim poderá ser garantida à pessoa idosa os seus direitos como cidadãos.

Palavras-chave: políticas públicas, envelhecimento humano, idoso.

\section{Abstract}

\section{Evolution of public policies for the elderly in Brazil}

The largest population longevity is one of the greatest achievements of mankind, because of technological and scientific advances people have lived longer. In Brazil, this reality is not different, the country is going to be one of the countries with the highest percentage of elderly people in the population. The increase in the elderly population brings new challenges for society, so it has become essential to discuss the public policy of the elderly at the present time. Given this context, this study aimed to describe, through a literature review, the evolution of public policies to the elderly in Brazil. It was concluded that the public policies for the elderly in Brazil have advanced significantly in the last decades. The Federal Constitution of 1988, The National Policy of the Elderly, the Statute of the Elderly and the National Policy on the Health of the Elderly were the main achievements of this process. However, despite the advances and achievements in practice to guarantee the rights of the elderly still have not been implemented effectively. For this reason, the implementation of public policies continues to be the main challenge to be overcome, since only then can the elderly be guaranteed their rights as citizens.

Key-words: public policies, human aging, elderly.

\section{Resumen}

\section{Evolución de las políticas públicas a la persona mayor en Brasil}

La mayor longevidad poblacional es una de las mayores conquistas de la humanidad, gracias a los avances tecnológicos y científicos, las personas pasan a vivir más tiempo. En Brasil esta realidad no es diferente, el país camina a pasos agigantados para convertirse en uno de los países con mayor porcentaje de adultos mayores en su población. El aumento de ese grupo de edad trae consigo nuevos desafíos para toda la sociedad, por lo que es esencial discutir en la actualidad sobre políticas públicas de las personas mayores. Ante este contexto, este estudio tuvo como objetivo describir por medio de una revisión de literatura, sobre la evolución de las 
políticas públicas al adulto mayor en Brasil. Se concluyó que las políticas públicas para los ancianos en Brasil avanzaron significativamente en las últimas décadas. La constitución Federal de 1988, La Política Nacional de la Persona Mayor, el Estatuto de la Persona Mayor y la Política Nacional de Salud de la Persona Mayor fueron las principales conquistas de ese proceso. Sin embargo, a pesar de los avances y logros, en la práctica la garantía de los derechos de la persona mayor aún no se ha concretado de forma efectiva. Por eso, la operacionalización de las políticas públicas sigue siendo el principal desafío a ser superado, pues sólo así podrá garantizarse la persona mayor de sus derechos como ciudadanos.

Palabras-clave: políticas públicas, envejecimiento humano, anciano.

\section{Introdução}

O envelhecimento da população mundial é um fenômeno atual sem precedentes. Estamos inseridos em um importante processo de transição do perfil demográfico e epidemiológico que ocasionará em um breve espaço de tempo profundas mudanças em toda sociedade. A população mundial tem passado nos últimos tempos por um processo acelerado de envelhecimento, e a maioria dos países do mundo tem experimentado uma elevação no número e na proporção de idosos em sua população. De acordo com o relatório da Organização das Nações Unidas, entre os anos de 2015 e 2030, o número de pessoas com mais de 60 anos deve crescer $56 \%$, passando dos atuais 901 milhões para 1,4 bilhões. Estimase ainda, que, por volta de 2050, a população global de idosos seja mais que o dobro da de 2015, atingindo cerca de 2,1 bilhões de idosos. No Brasil, esse cenário também não é diferente, estima-se que, por volta de 2050, o número de brasileiros com mais de 60 anos terá saltado dos atuais 24 milhões para 64 milhões, número este que colocará o país na sexta colocação entre os países com maior quantidade de pessoas na faixa etária idosa [1].

A maior longevidade populacional é com toda certeza uma das maiores conquistas da história da humanidade, graças aos avanços e melhorias no setor de saúde, nos hábitos e nas condições de vida, assim como, a redução da mortalidade infantil e da mortalidade geral, as pessoas passaram a viver mais tempo. Todavia, o acréscimo do número de idosos na população traz consigo também novas demandas políticas, sociais e econômicas que serão grandes desafios para o estado, sociedade e ao próprio idoso e suas famílias. Não restam dúvidas que esta transformação social terá impacto direto em todos os setores da sociedade brasileira, como previdência e assistência social, transportes, educação, consumo de bens e serviços, habitação, segurança pública, saúde, mercado de trabalho, economia e outros [1,2].

Este novo cenário vai obrigar a sociedade brasileira a ter que repensar os seus planos para o futuro que se aproxima, pois, as dificuldades para cuidar de uma população que está cada vez mais envelhecida será extremamente desafiadora. O Brasil enfrentará com 0 processo de envelhecimento de sua população um dos maiores desafios de sua história. Mas, o mais grave é que o país não está preparado para essas transformações, somente agora os gestores públicos começam a despertar lentamente para essa questão, enquanto a sociedade civil parece ignorar o problema. Desse modo, as famílias tentam administrar como podem aumentar a longevidade de seus pais e avós, mas a triste realidade é que não existem na atualidade estruturas necessárias para lidar com os grandes números associados ao envelhecimento da população idosa brasileira [1].

Fica evidente, dessa forma, a necessidade de se criar políticas públicas que atendam a questão do envelhecimento populacional brasileiro, pois soluções paliativas improvisadas não serão capazes de fazer frente às demandas específicas associadas ao processo de envelhecimento. Os idosos precisarão cada vez mais de suporte por parte de instituições públicas e organizações privadas, além de amigos e familiares. Por isso, é fundamental a elaboração de políticas públicas específicas e efetivas que possam garantir as pessoas idosas um processo de envelhecimento com subsistência, dignidade e qualidade de vida [1]. Assim, trazer para a agenda brasileira a questão do envelhecimento e as políticas públicas é essencial para o processo de avaliação de tais políticas, assim como para contribuir para sua efetividade e aperfeiçoamento de ações de proteção e assistência voltadas à população idosa [3].

Políticas públicas à pessoa idosa no Brasil

Pode-se dizer que as políticas de ação ao direito e defesa dos idosos começaram a ser discutidas internacionalmente a partir da década de 80. Historicamente, o primeiro marco desse movimento foi a realização da Primeira Assembleia Mundial sobre o Envelhecimento, da 
Organização das Nações Unidas (ONU). A respectiva assembleia ocorreu em Viena na Áustria, em 1982, com representantes de diversos países de todo o mundo, incluindo o Brasil. Em desfecho a esse evento, foi redigida a Carta de Viena, um Plano de Ação Internacional sobre o Envelhecimento Humano, com o intuito de alertar para a necessidade de planejamento de uma política de atendimento ao idoso nas áreas social, econômica, médica e legal. Foi colocado nessa ocasião que o envelhecimento bem-sucedido somente seria possível se houvesse uma parceria entre o Estado e a sociedade civil, na qual se deveriam contemplar os campos da cidadania, saúde, moradia, do trabalho e bem-estar. A realização da respectiva assembleia internacional foi, portanto, um acontecimento significativo, visto que colocou o envelhecimento populacional na agenda das políticas públicas mundiais [1-6].

Os objetivos traçados na Carta de Viena eram de garantir a segurança econômica e social da população idosa, bem como identificar as oportunidades para a sua integração ao processo de desenvolvimento dos países. Um dos principais resultados do plano de Viena foi colocar na agenda internacional as questões relacionadas ao envelhecimento individual e populacional. O pano de fundo eram as condições de vida dos idosos. Percebia-se a necessidade da "construção" e do reconhecimento da pessoa idosa como um novo ator social, contemplando as suas necessidades e especificidades. Parte das recomendações visava promover a independência e fortalecer as condições de saúde física, cognitiva, mental e financeira para garantir a autonomia do idoso. Foi a partir da Assembleia de Viena que o Brasil passou a incorporar, de forma mais assertiva, a questão do envelhecimento em sua agenda política. Até essa época as políticas brasileiras para com a população idosa eram direcionadas apenas para o provimento de renda e serviços médicos especializados, predominando a visão de vulnerabilidade e dependência dessa população. Vale dizer que esse momento coincidiu com o processo de redemocratização que estava a ocorrer no país [1,2].

Com a Nova República, veio a possibilidade da formação da Assembleia Nacional Constituinte, que resultou na Constituição Cidadã de 1988. Com a constituição de 88 os idosos passaram a ter reconhecido e assegurado os seus primeiros direitos sociais. Nesse período, os idosos já se destacavam como um grupo crescente e, particularmente representado pelos aposentados, começava a pressionar e discutir a situação dos idosos no país, a necessidade de espaços de participação, e reconhecimento de seu valor e de seus demais interesses. A partir desse momento, os idosos passaram a buscar juntamente com os profissionais das poucas instituições públicas e privadas que objetivavam atender as suas necessidades, a implantação pelos governos das recomendações contidas nas agendas internacionais [7].

A Constituição de 1988 foi à primeira constituição brasileira a contar com um capítulo de Ordem Social, Capítulo, este, que trata das questões da família, da criança, do adolescente e do idoso. Neste documento, no seu art. 230, por exemplo, ressalta que deve ser responsabilidade da família, da sociedade e do Estado o apoio aos idosos, de modo que seja assegurada a eles a participação na comunidade, à defesa da dignidade e do bem-estar e garantido o direito à vida. Em seu primeiro inciso, o artigo estabelece que os programas de cuidados dos idosos sejam executados preferencialmente em seus lares. $O$ segundo inciso amplia para todo o território nacional uma iniciativa que já vinha sendo observada em alguns municípios desde o início da década de 1980: a gratuidade dos transportes coletivos urbanos para as pessoas com 65 anos ou mais. Outro avanço da Constituição de 1988 , no art. $7^{\circ}$ do capítulo dos Direitos Sociais, diz respeito à proibição de diferenças de salário, de exercício de funções e de critério de admissão por motivo de sexo, idade, cor ou estado civil [1].

Ocorreu com a Constituição Federal de 1988 um grande avanço em políticas de proteção social aos idosos brasileiros. No seu desenvolvimento foram levados em consideração alguns princípios e diretrizes discutidas na Assembleia de Viena. Com a nova Constituição foi introduzido o conceito de seguridade social, fazendo com que a rede de proteção social deixasse de estar vinculada apenas ao contexto estritamente social-trabalhista e assistencialista, e passasse a partir de então a ter uma conotação de direito de cidadania. $O$ resultado foi que o Brasil passou a ser um dos pioneiros na América Latina na implementação de uma política de garantia de renda para a população. Acesso à saúde e educação também foram garantidos para todos, bem como a assistência social para a população necessitada $[1,2]$.

Como referido anteriormente, com a nova Constituição a participação da sociedade civil no desenvolvimento de políticas públicas foi garantida, este acontecimento foi imprescindível para a elaboração da Lei o 8.842 que dispõe sobre a Política Nacional do Idoso no Brasil (PNI). Regulamentada em 1996 pelo Decreto no 1948, a PNI possui como princípios à integração, a autonomia e a participação efetiva dos idosos na comunidade, de modo que estes exerçam a sua cidadania, com direitos e dignidade [8]. Um dos princípios norteadores da PNI foi o de 
estabelecer uma política de direito ao idoso, com garantia de renda, de vínculos relacionais, proteção social e promoção da cidadania em ações executadas nos municípios, com a parceria da sociedade civil [9]. Ou seja, seus objetivos principais foram o de assegurar ao idoso todos os direitos de cidadania, sendo a família, a sociedade e o Estado os responsáveis em garantir sua participação na comunidade, defender sua dignidade, bem-estar e direito à vida. Cabendo aos poderes públicos e à sociedade a aplicação dessa lei, atentando para as diferenças sociais, econômicas e regionais [2,4]. Em síntese, a política do idoso nasce para ratificar questões fundamentais como os princípios de que o envelhecimento diz respeito a toda a sociedade e não somente às pessoas idosas; de que as transformações necessárias na estrutura social exigem que o idoso seja o agente e o destinatário delas; e de que as pessoas idosas têm direito ao desenvolvimento de ações em todas as políticas setoriais $[7,10]$.

Dando seguimento às diretrizes lançadas pela Constituição Federal de 1988 e a criação do PNI, outra medida essencial veio resgatar os princípios e diretrizes constitucionais. Essa medida refere-se à criação do Estatuto do Idoso, por meio da Lei o 1.074 que entrou em vigor em $1^{\circ}$ de janeiro de 2004 . O estatuto surge em parte como reflexo da não implementação da PNI e por isso mesmo reitera vários de seus dispositivos, com o intuito de "regular os direitos assegurados às pessoas com idade igual ou superior a 60 (sessenta) anos" (Brasil, 2003, art. $1^{\circ}$ ). O estatuto reafirma o direito da pessoa idosa a educação, cultura, lazer e esporte (art. 20), bem como regulamenta que o poder público criará oportunidades de acesso do idoso à educação (art. 21) [11].

O respectivo estatuto conta com 118 artigos sobre diversas áreas dos direitos fundamentais, incluídas as necessidades de proteção dos idosos, visando reforçar as diretrizes contidas na PNI. Além de incluir leis e políticas já aprovadas, agrega novos elementos e enfoques, atribuindo um tratamento integral ao estabelecimento de medidas destinadas a proporcionar o bem-estar dos idosos [4]. O Estatuto do Idoso em conjunto com a PNI, é um dispositivo de Estado formado por um conjunto de normas e diretrizes para a formulação e execução de políticas públicas e serviços destinados à população idosa [12]. Ele é considerado um marco para as políticas dirigidas aos idosos no sentido que reconhece, por lei, os direitos e deveres dessa população, assegurando prioridades e os protegendo de maus-tratos a partir de uma legislação específica garantindo ao idoso acesso aos direitos fundamentais que se apoiam no direito à vida, à saúde, à alimentação, à educação, ao esporte, ao lazer, ao trabalho, à cidadania, à liberdade, à dignidade, ao respeito e à convivência familiar e comunitária $[6,13]$.

De certa forma, a ideia do Estatuto nasceu da crítica em relação à falta de efetividade $e$ não realização de inúmeras medidas de proteção e ações previstas na Lei que instituiu a PNI. A proposta de uma lei que trouxesse uma proteção específica ao grupo de pessoas idosas (grupo social vulnerável) também foi formada a partir da experiência social do Estatuto da Criança e do Adolescente. Assim, em 2001, a Câmara dos Deputados constituiu uma comissão especial, composta de vários deputados pertencentes a vários partidos políticos, para examinar as propostas ou projetos de lei, que tratavam do Estatuto do Idoso. O movimento social do idoso também foi convidado pela comissão para participar dos debates, fato que legitimou 0 processo legislativo, principalmente pela ativa participação dos representantes dos cinco fóruns regionais da política nacional do idoso: Norte, Nordeste, Centro Oeste, Sudeste e Sul, bem como de outras várias organizações não governamentais que atendem aos idosos, em todos os estados brasileiros. Diante dessa mobilização social, foi organizado em Brasília um seminário sobre o Estatuto do Idoso, que contou com cerca de 500 participantes e resultou em rica contribuição ao projeto do senador Paulo Paim, na qual foi considerado o mais pertinente aos interesses dos idosos. Somados todos esses esforços, o projeto foi aprovado, em outubro de 2003, após dois anos de tramitação no Congresso, com vigência a partir de 1ํ de janeiro de 2004 [14].

Seguramente, o Estatuto do Idoso é um dos principais instrumentos de direito da pessoa idosa no Brasil, sua aprovação representou um passo importante da legislação brasileira, ele ratifica os princípios que nortearam as discussões sobre os direitos humanos dessa população, cabendo ao Estado, à Sociedade e à Família a responsabilidade pela proteção e garantia desses direitos [4]. Embora seja alvo de críticas por sua ineficácia, o Estatuto do idoso tem um grande mérito, pois criou um sistema de garantias de direitos da pessoa idosa, que, apesar de vários percalços, tem buscado efetivar os direitos sociais dos idosos brasileiros. O sistema de garantias previsto no Estatuto é composto pelas seguintes instituições/órgãos: Conselhos do Idoso; Sistema Único de Saúde (SUS); Sistema Único de Assistência Social (Suas); Vigilância em Saúde; Poder Judiciário; Defensoria Pública; Ministério 
Público; e Polícia Civil. A eficiência dessa rede de garantias é uma das possibilidades para que a efetividade dos direitos das pessoas idosas se torne efetivas [14].

No que diz respeito à área da saúde, a criação de políticas de atenção específicas à saúde da população idosa é extremamente importante, pois uma das maiores demandas colocadas pela população idosa é por serviços de saúde. Por isso, é fundamental conhecer o perfil de morbimortalidade da população idosa, para que se possa definir o planejamento e a elaboração de políticas para melhorar as suas condições de vida e saúde [10]. Por conseguinte, como parte dos desdobramentos da PNI, foi promulgada pela Portaria $\mathrm{n}^{-1} 1.395$, de 10 de dezembro de 1999, a Política Nacional de Saúde do Idoso (PNSI), que foi posteriormente atualizada pela Portaria oㅡ 2.528, de 19 de outubro de 2006, que instituiu a Política Nacional de Saúde da Pessoa Idosa (PNSPI). Esta política apresenta como finalidade "recuperar, manter e promover a autonomia e a independência dos indivíduos idosos, direcionando medidas coletivas e individuais de saúde para esse fim, em consonância com os princípios e diretrizes do Sistema Único de Saúde". A PNSPI tem como desafio a articulação do complexo sistema de saúde pública às necessidades da população idosa, numa realidade assinalada pela iniquidade social. Entre as diretrizes desta política, ressalta-se a promoção do envelhecimento ativo e saudável, que enfatiza a necessidade de "facilitar a participação das pessoas idosas em atividades sociais, grupos de terceira idade, atividade física, conselhos de saúde locais e conselhos comunitários onde o idoso possa ser ouvido e apresentar suas demandas e prioridades" [11,15].

A PNSPI define que a atenção à saúde dessa população terá como porta de entrada a Atenção Primária à Saúde, tendo como referência a rede de serviços especializada de média e alta complexidade [15]. Essa política visa à promoção do envelhecimento saudável, à prevenção de doenças, à recuperação da saúde, e também à preservação, melhoria e reabilitação da capacidade funcional dos idosos com 0 intuito de assegurar-Ihes sua permanência no meio em que vivem de maneira independente [4]. A PNSPI destaca que a capacidade funcional da pessoa idosa deva ser um balizador das ações dos serviços de saúde e acena para a necessidade de efetivação de políticas de cuidado para a população idosa frágil, insistindo na necessidade de apoio às famílias com idosos e na capacitação para os profissionais para atendimento das necessidades dos idosos. Vale salientar, que a PNSPI teve origem de um consenso estabelecido a partir de um amplo debate com vários pesquisadores, técnicos, gerontólogos e geriatras de renome nacional de todo o país, que foram convidados pelo Ministério da Saúde a propor uma estratégia de implementação da PNI na saúde pública [16].

Em sequência, no ano de 2006, os gestores das três esferas de governo discutiram e acordaram um "pacto de gestão", pautado no respeito às diferenças regionais, e cuja avaliação e cobrança pelo Ministério da Saúde aconteceria com base em resultados. Esse processo mais acirrado de discussão culminou com a publicação do Pacto pela Saúde, que revê e enfatiza a responsabilidade e as atribuições das diferentes instâncias governamentais. O Pacto pela Saúde congrega o Pacto pelo SUS, o Pacto pela Gestão e o Pacto pela Vida. O Pacto pelo SUS reafirma este sistema de saúde como uma política de Estado, assim, como os princípios que o norteiam desde a sua origem: a universalidade, a integralidade e a equidade. $O$ Pacto pela Gestão define as principais políticas e metas pactuadas pelas três esferas de governo para o território nacional, e o Pacto pela Vida retoma algumas normas operacionais básicas do SUS, e incorpora muitos de seus conceitos, entretanto, ele o faz com uma abordagem bastante diferente, estabelecendo que a atenção ao idoso deva ser prioritária [16].

Em resumo, observa-se que com a criação do SUS houve expressiva melhoria do acesso aos serviços de saúde em todo país, contudo, no que se refere à parcela idosa, podese inferir que os avanços reflitam muito mais a implementação do SUS do que propriamente a influência ou a incorporação da PNI nesse processo. Provavelmente em razão disso, 0 legislador repetiu no Estatuto do Idoso as mesmas determinações para o direito à saúde, existentes na $\mathrm{PNI}$, exigindo ainda prioridade à parcela idosa nos serviços públicos e privados de atendimento. Porém, o próprio Estatuto do Idoso tem sido descumprido, se considerado o direito à prioridade (art. $3^{\circ}$, parágrafo único), na formulação e na execução de políticas públicas específicas, e na destinação privilegiada de recursos públicos nas áreas relacionadas com a proteção social. Muitas vezes, os aspectos formais garantidos no plano legal não correspondem ou demoram a se expressar em mudanças práticas de direitos e coberturas. Assim, a não efetivação da PNI na saúde reflete questões de ordem estrutural ou de escolha política no sistema geral de saúde pública que afeta diretamente os programas voltados à pessoa idosa [16]. 
Diante dos aspectos apresentados, pode-se inferir que de forma geral as Políticas Públicas voltadas para as pessoas idosas no Brasil evoluíram de forma significativa desde a década de 80. Ao longo desse período, o país conseguiu desenvolver diversos recursos legais de atenção às pessoas idosas, entre estes se pode destacar como as principais conquistas desse processo a nova Constituição Federal de 1988, A Política Nacional do Idoso, o Estatuto do Idoso e a Política Nacional de Saúde da Pessoa Idosa.

Os direitos das pessoas idosas regulamentados pela Constituição Federal de 1988, inicialmente de cunho protetivo, e fortemente marcados pela visão negativa da velhice, foram sendo paulatinamente ampliados a partir da promulgação de outras leis, como, por exemplo, a Lei oㅜ 8.842, de 4 de janeiro de 1994, que dispõe sobre a PNI, e a Lei no 10.741 , de 1ㅇ de outubro de 2003, que dispõe sobre o Estatuto do Idoso, ambas gerando repercussões em termos legais e políticos [11]. A Constituição Federal de 1988 inovou ao exigir a efetiva proteção à pessoa idosa por parte do Estado, da sociedade e da família. A partir desta nova constituinte, ter uma "velhice digna" passou a ser um direito primordial de todos. Já em termos infraconstitucionais, a PNI e o Estatuto do Idoso representam as principais leis ordinárias de proteção da pessoa idosa, reforçando os princípios e diretrizes contidos na Constituição brasileira de 88 [14]. No que diz respeito à área da saúde, a PNSPI, por meio do Sistema Único de Saúde propõe um atendimento específico às necessidades dos idosos, garantindo o acesso ao sistema e ao cuidado integral a saúde.

$\mathrm{Na}$ atualidade, a questão do envelhecimento populacional passou a ter muito mais visibilidade, hoje os idosos são reconhecidos como um grupo etário sujeito a necessidades que implicam ações específicas. Contudo, apesar dos avanços e conquistas alcançadas, os idosos parecem ainda não serem reconhecidos como um grupo social, visto não usufruírem adequadamente de alguns direitos elementares de cidadania, como renda digna, assistência médica e saúde, segurança, espaço socialmente produtivo e muitas outras condições que promovem a saúde e a qualidade de vida [7].

Embora o envelhecimento da população brasileira tenha se tornado uma realidade incontestável, ainda estamos longe de alcançar o estado de direito pleno para as pessoas idosas, mas, o mais grave é que o governo e a sociedade brasileira não tratam essa realidade como um fato prioritário e emergente e, nem estão preparados para atender essa nova demanda. Isso explica o fato de não existir, na agenda política nacional, uma discussão consistente sobre o processo de envelhecimento que inclua a efetivação dos direitos dos idosos [17].

Ocorre que, transcorridos quase três décadas da redemocratização do país e de todo esse labor legislativo pró-idoso, as políticas públicas para o envelhecimento não foram ainda totalmente efetivadas. Apesar dos avanços e conquistas nota-se que na prática a garantia desses direitos ainda estão longe de ser totalmente concretizada [14]. Mesmo reconhecendo a existência de bons programas e serviços mantidos em algumas cidades em diferentes regiões do país, no que diz respeito à política social nacional para velhice, esta cresceu no discurso, mas estancou na prática. Em alguns casos recuou, sobretudo quando se trata de questões referentes à pobreza econômica e à seguridade social. Reconhecer direitos não basta, é necessário proporcioná-los [7].

O futuro é preocupante especialmente em tempos de crise econômica e social que o país atravessa no momento. $O$ achatamento progressivo do valor das aposentadorias e a crescente inflação geram nos cidadãos a perspectiva da perda da independência econômica e a dependência dos filhos adultos ou de outros. As dificuldades de acesso ao atendimento à saúde, a violência, os preconceitos, as reduzidas oportunidades de participação social fazem do tempo da velhice um tempo de constrangimento e isolamento social [7].

Conclusão

Com o envelhecimento populacional e a crescente longevidade dos indivíduos, fica clara a necessidade de uma mudança de olhar em relação a essa fase do desenvolvimento humano. A velhice na sociedade atual pode se estender por várias décadas, o que torna fundamental a criação de meios para garantir um envelhecimento ativo e com qualidade de vida para todos os cidadãos. Desse modo o tema envelhecimento populacional deve estar presente nas principais agendas políticas e sociais brasileiras, pois este será provavelmente 
um dos maiores desafios da história do país, com impactos avassaladores sobre todos os setores da sociedade. A trajetória a ser trilhada será longa e precisará envolver e sensibilizar toda a sociedade civil e o poder público. Se, por um lado, o Estado apresenta uma fleuma na implementação das políticas, por outro, a sociedade civil necessita de uma maior mobilização e conscientização acerca da necessidade de resgatar a dignidade e a cidadania das pessoas idosas. Somente a partir de uma ação conjunta destes dois protagonistas, uma sociedade mais inclusiva e justa poderá ser vislumbrada.

1. Brasil. Brasil 2050: Desafios de uma nação que envelhece. Câmara dos Deputados, Centro de Estudos e Debates Estratégicos, Consultoria Legislativa; relator Cristiane Brasil; consultores legislativos Alexandre Cândido de Souza (coord.), Alberto Pinheiro [et al.]. Brasília: Câmara dos Deputados, Edições Câmara; 2017.

2. Alcântara AO, Camarano AA, Giacomin KC. Política nacional do idoso: velhas e novas questões. Rio de Janeiro: Ipea; 2016. 615 p.

3. Damasceno CKCS, Sousa CMM. Análise sobre as políticas públicas de atenção ao idoso no Brasil. R Interd 2016;9(3):185-90.

4. Rodrigues RAP, Kusumot L, Marques S, Fabrício SCC, Rosset-Cruz I, Lange C. Política nacional de atenção ao idoso e a contribuição da enfermagem. Texto \& Contexto Enferm 2007;16(3):536-45.

5. Bruno LMSM. Operacionalização das políticas de atenção ao idoso: um olhar avaliativo sobre algumas experiências no município do Rio de Janeiro [Dissertação]. Rio de Janeiro: Instituto de Medicina Social - Universidade do Estado do Rio de Janeiro; 2009. 80p.

6. Correa MR, França S, Hashimoto F. Políticas Públicas: a construção de imagens e sentidos para o envelhecimento humano. Estud Interdiscipl Envelhec 2010; 15(2):21938.

7. Rauth J, Py L. A história por trás da lei: o histórico, as articulações de movimentos sociais e científicos, e as lideranças políticas envolvidas no processo de constituição da política nacional do idoso. In: Alcântara AO, Camarano AA, Giacomin KC. Política nacional do idoso: velhas e novas questões. Rio de Janeiro: Ipea; 2016.

8. Ramos PRB, Logrado YSC, Perdigão VF, Lima GKS, Caldas AM. Políticas Públicas direcionadas ao Idoso: Aplicabilidade do artigo 4을 do decreto no 1.948/96. II Jornada Internacional de Políticas Públicas. São Luís, MA, 2005.

9. Correa MR, França S, Hashimoto F. Políticas Públicas: a construção de imagens e sentidos para o envelhecimento humano. Estudos Interdisciplinares sobre o Envelhecimento 2010;15(2):219-38.

10. Camarano AA, Kanso S, Fernandes, D. Brasil envelhece antes e pós-PNI. In: Alcântara AO, Camarano AA, Giacomin KC. Política nacional do idoso: velhas e novas questões. Rio de Janeiro: Ipea; 2016.

11. Assis MG, Dias RC, Necha RM. A universidade para a terceira idade na construção da cidadania da pessoa idosa. In: Alcântara AO, Camarano AA, Giacomin KC. Política nacional do idoso: velhas e novas questões. Rio de Janeiro: Ipea; 2016.

12. Justo JS, Rozendo AS. A velhice no Estatuto do Idoso. Estudos e Pesquisas em Psicologia 2010;10(02):471-479.

13. Ceneviva W. "Estatuto do Idoso, Constituição e Código Civil: a terceira idade nas alternativas da lei". A Terceira Idade 2004;15(30):7-23.

14. Alcântara OA. Da política nacional do idoso ao estatuto do idoso: A difícil construção de um sistema de garantias de Direitos da pessoa idosa. In: Alcântara AO, Camarano AA, Giacomin KC. Política nacional do idoso: velhas e novas questões. Rio de Janeiro: Ipea; 2016.

15. Brasil. Ministério da Saúde. Secretaria de Atenção à Saúde. Departamento de Atenção Básica. Envelhecimento e saúde da pessoa idosa / Ministério da Saúde, Secretaria de Atenção à Saúde, Departamento de Atenção Básica - Brasília: Ministério da Saúde; 2006.

16. Giacomin KC, Maio GI. A PNI na área da saúde. In: Alcântara AO. In: Alcântara AO, Camarano AA, Giacomin KC. Política nacional do idoso: velhas e novas questões. Rio de Janeiro: Ipea; 2016. 
17. Berzins MAVS, Giacomin KC, Camarano AAA. Assistência social na política nacional do idoso. In: Alcântara AO, Camarano AA, Giacomin KC. Política nacional do idoso: velhas e novas questões. Rio de Janeiro: Ipea; 2016. 